\title{
Synthesis and Biological Activity of Novel Platencin Derivatives
}

\author{
Dennis C.J. Waalboer \& Floris P.J.T. Rutjes \\ Radboud University Nijmegen, \\ Institute for Molecules and Materials, Netherlands. \\ Email: F.Rutjes@science.ru.nl
}

\begin{abstract}
The biological mode of action of platencin, a potential lead molecule for a new class of antibiotics, is detailed. Furthermore, enantiopure syntheses of several platencin derivatives are described, of which the core structure can be accessed in two exceedingly simple steps from commercially available starting materials. Furthermore, the antibiotic properties of the derivatives was evaluated.
\end{abstract}

Keywords: antibiotics; dehydrohomoplatencin; platencin; resistance.

\section{$1 \quad$ Introduction}

The emergence of resistant pathogens is a rapidly increasing concern to society and has been identified by the World Health Organization (WHO) as one of the three greatest threats to human health. According to the Infectious Diseases Society of America (IDSA), in 2005 more than 50\% of the Staphylococcus aureus infections encountered in hospitalized patients involved methicillin resistant Staphylococcus aureus (MRSA). This bacterium alone is responsible for 19.000 deaths annually in the USA and has become a prime concern in hospitals. The recent call of the IDSA to develop ten new antibiotics by 2020 further illustrates the pressing need for new classes of antibiotics. However, with only three new classes of antibacterial agents approved for clinical use since 1962 [1], the pharmaceutical industry lags far behind.Since the 1960's, fighting microbial resistance mainly relied on modification of existing antibiotics. However, because it becomes increasingly more difficult to manipulate existing antibiotics while retaining the activity, also in this area the pipeline is running dry. In 2009 only two new antibiotics entered the market; telavancin [2,3], a semi-synthetic derivative of vancomycin, and besifloxacin [2], a fourth-generation fluoroquinolone. More strikingly, in 2004, out of the 506 drugs in late-stage clinical testing by the 15 largest pharmaceutical companies, only six were new antibacterials, which were all derivatives of known antibiotics [4]. One of the main reasons for the declining interest of the pharmaceutical industry in the development of new antibiotics is the inevitable paradox that although the rapidly emerging resistance calls for more antibiotics, a new antibiotic, to which no resistance exists, will preferably be held in reserve 
until all other therapies fail. Ending up with a second-line therapeutic agent will certainly not appeal to the pharmaceutical industry when it costs $\$ 1,800$ million on average and 10-15 years to bring a new drug to the market [5]. Additionally, chronic diseases, where drugs are prescribed for years or even lifelong, are financially more attractive than the treatment of infections, where medication is typically used for weeks. To steer clear of a health-care calamity, several incentives for the pharmaceutical industry to develop new antibiotics are investigated. These include patent extension for one of the company's drugs, limiting liability for adverse effects and advanced purchase commitment from the government. Revision of clinical trial protocols to facilitate approval of new antibiotics by the US Food and Drug Administration (FDA) is also discussed, but has so far not led to major changes [6].

In this respect, the recent discovery of potent inhibitors of an essential and unexploited bacterial pathway by Merck is especially encouraging. Using antisense RNA silencing, researchers systematically screened 250.000 natural product extracts for inhibition of the fatty acid synthesis in bacteria to find two potent inhibitors of this pathway, platensimycin (1) [7] and platencin (2) (Figure 1) [8]. Both compounds were recovered from soil extracts collected in South Africa and Spain, respectively, and showed potent broad-spectrum Grampositive antibacterial activity.

Figure 1 Structures of (-)-platensimycin (1) and (-)-platencin (2).

The bacterial type II fatty acid synthesis (FAS II) [9] differs significantly from the type I fatty acid synthesis (FAS I) [10] in animals and humans. Bacteria rely on several distinct enzymes for the production of essential fatty acids, but in humans the overall reaction is performed by one large dimeric enzyme which incorporates no less than seven different catalytic sites. Because the protein sequences and the active sites of the two types differ significantly, the type II fatty acid synthesis is considered an attractive target for the development of new antibiotics [11]. As detailed in Figure 2, the first committed step in the FAS II pathway is the carboxylation of acetyl-CoA which is carried out by acetyl-CoA carboxylase (ACC) [12]. This multi-subunit enzyme is encountered in different forms in virtually all living organisms including plants, where plant-ACC is the target of widely used herbicides. The recent discovery of several bacterial ACC inhibitors provided promising results for their use as antibiotics [13]. In the next 
step, FabD, a malonyl-CoA:ACP transacylase, catalyzes the transfer of a malonyl group from coenzyme A (CoA) to the acetyl carrier protein (ACP) [14]. This enzyme is present in excess and is not considered to play an essential role in fatty acid synthesis. Conversely, the subsequent condensation of malonyl-ACP with acetyl-CoA to form $\beta$-ketobutyryl-ACP, catalyzed by FabH, is a crucial initiating step in the fatty acid synthesis cycle. However, targeting this enzyme across a wide range of bacteria is challenging because of structural variations in the substrate binding site of $\mathrm{FabH} \mathrm{[15].} \mathrm{These} \mathrm{architectural}$ differences determine the fatty acid profile of an organism which causes e.g. Escherichia coli to produce predominantly straight-chain fatty acids and Streptomyces glaucescens to produce both straight and branched chain fatty acids. Nonetheless, several inhibitors of $\mathrm{FabH}$ have been reported of which platencin (2) is the most potent one $\left(\mathrm{IC}_{50}=3.91 \mu \mathrm{g} \mathrm{mL} \mathrm{m}^{-1}\right.$ in $S$. aureus), demonstrating the viability of $\mathrm{FabH}$ as an antibiotic target [8].

In contrast to $\mathrm{FabH}$, the next enzyme in the cycle is highly conserved and only a single isoform is known in bacteria. This enzyme, FabG, is a reductase which catalyzes the reduction of a $\beta$-ketoacyl intermediate by NADPH. Interestingly, FabG is the only enzyme in the catalytic cycle that undergoes a substantial conformational change upon binding of its cofactor which could offer additional opportunities for drug development [16]. However, this enzyme is not rate limiting in the catalytic cycle which possibly explains why the few reported inhibitors of FabG only show moderate antibiotic activity [17]. In the next step, the alcohol of the $\beta$-hydroxyacetyl-ACP complex is eliminated by FabA or FabZ to give trans-2-acetyl-ACP. In contrast to FabZ, FabA is a bifunctional enzyme and also catalyzes the isomerization of trans-2-acetyl-ACP to cis-3acetyl-ACP, essential for unsaturated fatty acid synthesis. FabA is only present in Gram-negative bacteria and it is believed that Gram-positive bacteria, which also produce unsaturated fatty acids, utilize other isomerases such as FabM and FabZ $_{1}[18,19]$. FabZ is the primary dehydratase in the FAS II pathway and simple inhibitors have been reported that show good in vitro activity for Helicobacter pylori [20]. However, the equilibrium that is catalyzed by FabZ lies to the side of the $\beta$-hydroxyacetyl-ACP complex and is not rate-limiting which makes it a somewhat less attractive target for new antibiotics. Inhibition of the reductase FabI in the last step of the FAS II pathway is considered to have more potential and is already targeted by triclosan, which is an antimicrobial agent that is widely used in a variety of consumer products [21]. Unfortunately, several key pathogenic bacteria, including Streptococcus pneumoniae, use FabK for this reduction step, which makes FabI less interesting for the development of broad-spectrum antibiotics [22]. 
Figure 2 Schematic representation of the bacterial type II fatty acid synthesis. The color of the enzyme indicates the potential as an antibacterial target; black: little potential, orange: considerable potential, red: most potential [11].

After the reduction step, the product can re-enter the catalytic cycle, but now the first step is performed by the elongation condensing enzymes FabB and FabF instead of the initiating ezyme FabH. Bacteria that express FabA typically utilize FabB for elongation of unsaturated fatty acids. However, in the absence of FabB, the second elongation enzyme FabF carries out the elongation of both saturated and unsaturated acyl-ACP's [23]. The crucial role of FabF and its ubiquitous presence in bacteria make this an attractive target for new antibacterials and several inhibitors for FabF have been reported. The first ones were cerulenin [24] and thiolactomycin [25] which displayed only weak antibiotic activity, precluding clinical use. More recently, platensimycin (1) and platencin (2) were discovered both proving potent inhibitors of FabF $\left(\mathrm{IC}_{50}=\right.$ 0.13 and $1.95 \mu \mathrm{g} \mathrm{mL}^{-1}$ respectively in $S$. aureus). Despite the lower affinity of platencin (2) for FabF, the overall in vivo efficacy of both compounds is comparable because platencin (2) also inhibits the previously discussed initiating enzyme $\mathrm{FabH}\left(\mathrm{IC}_{50}=3.91 \mu \mathrm{g} \mathrm{mL}^{-1}\right.$ in $S$. aureus $)$. 


\section{Results and Discussion}

As a result of the intriguing structure and valuable antibacterial properties, platensimycin (1) and platencin (2) became prime targets for synthetic chemists, resulting in a large variety of synthetic routes to these natural products [26]. It is, however, rather unlikely that the natural products platensimycin (1) and platencin (2) will find application as drugs due to their complex structures and, especially, their poor pharmacokinetic properties. Instead, as with many natural products, derivatives will have to be synthesized with improved pharmacokinetic properties and synthetic accessibility. While for platensimycin (1) several close analogues and a small library of simple analogues have been developed [27], it is quite surprising that for platencin (2) only two papers appeared with analogues in which the tricyclic core was modified. In 2009 Snider et al. published a synthesis of nor-platencin (3), a close analogue of platencin which lacks the exo-methylene group (Figure 3) [28]. The researchers reasoned that the exo-methylene of platencin (2) might be superfluous as being merely a structural feature of the terpenoid precursor. In contrast to these expectations, nor-platencin (3) displayed a 4-16 fold lower activity than platencin (2) indicating that the exo-methylene significantly contributes to the activity of platencin.

Figure 3 Structures of nor-platencin and iso-platencin.

A second derivative, iso-platencin (4), was recently reported by Mulzer et al. who elaborated an intermediate of their synthesis of platencin to iso-platencin (4) [29]. The activity of iso-platencin (4) was comparable to that of platencin (2), but strikingly, for some bacteria, such as the key pathogen Enterococcus faecalis, all activity was lost.

We recently reported a total synthesis of platencin (2), based on the efficient high-pressure-mediated Diels-Alder reaction of perillaldehyde (5) with the Danishefsky diene resulting in intermediate (6) in $82 \%$ yield as a single diastereisomer (Scheme 1) [30]. This intermediate was then converted into the platencin core (12) in 8 steps, thereby representing one of the shortest formal syntheses of this natural product. Interestingly, in an attempt to functionalize aldehyde (6) with $\mathrm{TsOH}$ in benzene at $80^{\circ} \mathrm{C}$ tricyclic diene (7) was formed in a 
moderate yield of $48 \%$. The unique structure of this diene was unambiguously confirmed by X-ray crystallographic analysis [31].

Scheme 1 High-pressure Diels-Alder reaction and unexpected cyclization of aldehyde (6).

In Scheme 2, a plausible mechanism for the unexpected reactivity of aldehyde (6) is shown, which proceeds via the Prins reaction. The proposed reaction pathway starts with protonation of aldehyde (6), followed by nucleophilic attack of the isopropenyl moiety. The intermediate tertiary cation (9) can eliminate in two ways, leading to either the allylic or homoallylic alcohol. However, molecular modelling (MM2) clearly indicated that allylic alcohol (10) is the thermodynamic product. In the next step, protonation and elimination resulted in the formation of the allylic cation (11), which can undergo elimination to diene (7). It is interesting to note that examples of seven-membered ring formation via a Prins cyclization are rather rare and to the best of our knowledge no examples exist that yield a cycloheptadiene.

Scheme 2 Proposed mechanism for the Prins cyclization of diene (7).

Clearly, diene (7) bears strong resemblance to the core structure of platencin (12) (Scheme 2). An MM2 minimized overlap of both structures (not shown) revealed that the increased ring size of diene (7) does not alter the overall shape of the molecule compared to core structure (12) and only affects the orientation 
of the exo-cyclic double bond. The strong similarity of core structures (7) and (12), and the exceptionally short synthesis of diene (7) sparked our interest in the antibiotic properties of a platencin analogue incorporating the latter moiety. Therefore, the Prins cyclization was optimized.

Table 1 Optimization of the Prins cyclization step.

\begin{tabular}{ccccccc}
\hline Entry & Catalyst & Equiv & $\mathbf{T}\left({ }^{\circ} \mathbf{C}\right)$ & Additive & ${\text { Yield 7 }(\%)^{\mathbf{a}}}$ & ${\text { Yield 13 }(\%)^{\mathbf{a}}}^{\text {a }}$ \\
\hline 1 & TsOH & 0.5 & 80 & - & 67 & 11 \\
2 & TsOH & 0.5 & 80 & $\mathrm{MgSO}_{4}$ & n.r. & n.r. $^{\text {b }}$ \\
3 & TsOH & 0.1 & Dean Stark & - & 54 & 12 \\
4 & TsOH & 0.5 & 80 & hydroquinone & 44 & 7 \\
5 & $\mathrm{CSA}$ & 0.5 & 80 & - & 44 & 8 \\
$6^{\mathrm{c}}$ & $\mathrm{TfOH}$ & 1.5 & $0{ }^{\circ} \mathrm{C}$ to RT & - & 65 & 11 \\
\hline
\end{tabular}

${ }^{\mathrm{a}}$ Isolated yield. ${ }^{\mathrm{b}}$ n.r. $=$ no reaction. ${ }^{\mathrm{c}}$ Reaction performed in THF.

This reaction is generally catalyzed by Brönsted and Lewis acids such as $\mathrm{H}_{2} \mathrm{SO}_{4}, \mathrm{TsOH}, \mathrm{BF}_{3}$ and $\mathrm{AlMe}_{2} \mathrm{Cl}$ offering numerous possibilities for optimization [32]. In a preliminary screening of $\mathrm{H}_{2} \mathrm{SO}_{4}, \mathrm{BF}_{3} \cdot \mathrm{OEt}_{2}$ and $\mathrm{TsOH}$ as catalysts in the Prins reaction of aldehyde $(\mathbf{6})$, the latter acid clearly showed the best result according to TLC analysis and was selected for further optimization (Table 1). By shortening the reaction time to $30 \mathrm{~min}$, the yield of diene (7) was increased to $67 \%$ (entry 1). Interestingly, the reaction with $\mathrm{TsOH}$ also gave rise to a side reaction, namely isomerization of the isopropenyl group leading to ketone (13). In theory, trapping the eliminated water in the Prins reaction should drive the equilibrium to diene (7) so that the reaction was also performed in the presence of $\mathrm{MgSO}_{4}$ (entry 2) and under Dean Stark conditions (entry 3). Surprisingly, the addition of $\mathrm{MgSO}_{4}$ inhibited the reaction and only little conversion was achieved upon prolonged heating. Under Dean Stark conditions, the reaction proceeded smoothly, however, without leading to a higher overall yield. Furthermore, the addition of hydroquinone to the reaction (entry 4) to suppress possible radical polymerization of diene (7) or changing the catalyst to the slightly milder acid CSA (entry 5) only decreased the yield. On the other hand, reaction of aldehyde (6) with the stronger acid TfOH in THF at RT (entry 6) afforded the product in essentially the same yield as for entry 1, and thus represents a viable alternative to the thermal $\mathrm{TsOH}$ conditions.

In order to synthezise the full platencin derivative, the methyl group and propionic acid linker had to be installed. In the synthesis of platensimycin (1) 
this non-trivial challenge was first solved by Nicolaou, et al. [33]. Their strategy, which involved cross-metathesis with vinylboronic acid pinacol ester as the key step, was later also applied in their synthesis of platencin (2) [34]. Because of the structural similarity of diene (7) and the core structure of platencin (12), we decided to adopt the same strategy for the incorporation of the linker. The first step in this approach was $\alpha$-alkylation of diene 7 with methyl iodide (

Scheme 3). Although the reaction proceeded in good yield, the presence of a small amount of the corresponding diastereoisomer (7:1) was somewhat unexpected. No diastereoisomer formation was reported for this step in the syntheses of platensimycin and platencin by Nicolaou et al. In the second step, ketone (14) was allylated with allyl iodide to give alkene (15) in $76 \%$ as an inseparable mixture of diastereoisomers ( $\mathrm{dr}$ 10:3). With allyl bromide as the electrophile, also $O$-alkylation occurred to give enol ether (16) in $27 \%$ yield. Interestingly, upon GC analysis of the latter product, the thermal conditions efficiently promoted a Claisen rearrangement to give alkene (15) in the same $\mathrm{dr}$ of $10: 3$.

Scheme 3 Incorporation of the propionic acid linker.

The diastereomeric mixture of alkene (15) was reacted in the next step in a cross-metathesis reaction with vinylboronic acid pinacol ester (17). Unsure 
about the effect of the diene moiety on the reaction, we were pleased to find that the cross-metathesis proceeded well according to TLC analysis. However, after workup NMR analyses revealed a complex mixture of products. This can, at least in part, be attributed to the diastereomeric mixture used in the reaction and the formation of $E$ - and $Z$-isomers. Since the products were inseparable by flash chromatography, the mixture was reacted further in the oxidation of the vinylic borane (18) with $\mathrm{Me}_{3} \mathrm{NO}$ to give aldehyde (19) in 35\% yield over two steps (corrected for the dr of 10:3 of alkene (15)). Aldehyde (19) was the only diastereoisomer that was isolated and subsequently reacted in a Pinnick oxidation to give carboxylic acid (20) in $91 \%$ yield.

Scheme 4 Completion of platencin derivative (23).

The synthesis of the targeted platencin derivative (23), termed dehydrohomoplatencin, was completed using the methodology developed by Giannis and co-workers [35] and Nicolaou, et al. [34] Thus, aniline (21) was synthesized and subsequently coupled to carboxylic acid (20) with HATU and $\mathrm{Et}_{3} \mathrm{~N}$ in DMF to yield amide (22) in 70\% (Scheme 4). In the last step, the TMSE ester was deprotected by treatment with the fluoride donor TASF providing the completed derivative dehydrohomoplatencin $(\mathbf{2 3})$ in $57 \%$ yield.

With derivative (23) finally in hand, we determined its antibiotic profile and compared the results to the reported values of platensimycin (1) [36] and platencin (2) [37]. Much to our delight dehydrohomoplatencin (23) turned out to be virtually equipotent to natural products (1) and (2) and only for $S$. pneumoniae a striking loss of activity was observed (Table 2) [31].

Considering the lengthy sequence and moderate overall yield for the introduction of the C-3 linker in derivative (23), we became also interested in analogues incorporating linkers that are synthetically more readily accessible. In Scheme 5, the carbamate-linked derivative (26) is shown, which should in theory greatly facilitate the introduction of the linker. Moreover, replacement of the amide for a more electron-rich carbamate should also render the molecule more stable to hydrolysis. 
Table 2 MIC values of derivatives (23) on multiresistant bacteria.

\begin{tabular}{cccccc}
\hline \multirow{2}{*}{ Entry } & Organism & \multirow{2}{*}{ Resistance } & \multicolumn{2}{c}{ MIC $(\boldsymbol{\mu g} / \mathbf{m L})$ of compounds } \\
\cline { 3 - 5 } & S. aureus & MSSA & 1 & $\mathbf{2}$ & $\mathbf{1}$ \\
\hline 1 & S. aureus & MRSA & 1 & - & 0.5 \\
3 & S. aureus & er. R, ${ }^{\mathrm{a}}$ cl. S & 1 & - & 0.5 \\
4 & S. aureus & MSSA & 0.5 & 0.5 & 0.5 \\
5 & S. aureus & macrolid R & 1 & 1 & 1 \\
6 & E. faecalis & - & 2 & 2 & - \\
7 & E. faecalis & VRE & 2 & - & - \\
8 & E. faecium & - & 0.12 & - & 0.1 \\
9 & E. faecium & VRE & 0.12 & - & - \\
10 & CNS & - & 0.25 & - & - \\
11 & CNS & MRSE & 0.12 & 4 & 1 \\
12 & S. pneumoniae & - & $>16$ & - & - \\
13 & S. pneumoniae & macrolid R & $>16$ & - & - \\
14 & S. pneumoniae & penicillin R & $>16$ & - & - \\
\hline
\end{tabular}

${ }^{\mathrm{a}}$ er. R. = erythromycin R. ${ }^{\mathrm{b}}$ cl. S. = clindamycin S

Thus, alcohol (24) was synthesized by treatment of ketone (14) with LDA and formaldehyde in $50 \%$ yield as an easily separable mixture of diastereoisomers and $24 \%$ of recovered starting material. The relative configuration of both alcohols was readily assigned with NOESY. The challenging intermolecular coupling of the desired diastereoisomer of (24) with the hindered aniline (21) was achieved in a one-pot procedure involving carbonyldiimidazole (CDI) and DMAP in $33 \%$. Finally, deprotection was effected with TASF to give the carbamate derivative (26) in $47 \%$ yield. Although the overall yield over the three steps is low, sufficient material was obtained to determine the antibiotic profile of derivative (26). In contrast to our expectations, compound (26) did not show any antibiotic activity for MRSA or VREF and therefore no optimization of the synthetic pathway was performed.

Scheme 5 Synthesis of carbamate derivative (26).

Another derivative that was synthesized is triazole (27) (Scheme 6). In this analogue the amide is substituted for a triazole and the methyl group at the $\alpha$ - 
position of the ketone is absent. Again, these modifications were synthetically driven and aimed to considerably simplify the synthesis. We also realized that even though triazoles are bioisosteres of amides, the hydrogen bond donor interaction that the amide group in platencin has with the enzyme cannot be mimicked by the triazole, which might decrease the activity of the triazole derivative. Triazole (27) can be assembled in two steps via a 1,3-dipolar cycloaddition of azide (28) with alkyne (29) and subsequent TASF deprotection. A considerable advantage of the absence of the methyl group in alkyne (29) is that, in the case of diastereoisomer formation in the alkylation step, epimerization to the thermodynamic product should be possible.

Scheme 6 Retrosynthesis of triazole derivative (27).

The synthesis of azide (28) commenced with nitration of resorcinol, as developed by Giannis, et al. (Scheme 7) [35]. Treatment of resorcinol (30) with nitric acid and acetic anhydride in acetic acid yielded nitroresorcinol (31) in $35 \%$ together with $23 \%$ of regioisomer (32). Subsequent MOM protection of both phenol groups and reduction of the nitro group with $\mathrm{H}_{2}$ and $\mathrm{Pd} / \mathrm{C}$ afforded aniline (34) in good yield. The scalability and speed of this approach easily outweighs the low yield of the first step and made this the preferred synthetic pathway to aniline (34). In the last step, the azide was introduced via diazotransfer with triflyl azide to give azide (28) in low yield. No optimization was carried out since sufficient material was obtained to complete the synthesis of the derivative. 
The synthesis of the second cycloaddition partner was realized by alkylation of ketone 7 with 3-bromo-1-(trimethylsilyl)-1-propyne, which, after deprotection with $\mathrm{K}_{2} \mathrm{CO}_{3}$, yielded alkyne (29) in $74 \%$ yield over two steps b.r.s.m. (Scheme 8). Notably, the product was obtained as a single diastereoisomer and no additional epimerization step was required. According to the large coupling constant of $J=12.8 \mathrm{~Hz}$ for the $\alpha$-proton, the propargyl group must be in the equatorial position. In the final stage of the synthesis, alkyne (29) was reacted with azide (28) in a copper-catalyzed 1,3-dipolar cycloaddition reaction. Simple copper wire, routinely used for this reaction in our group, failed to give any reaction and the addition of copper iodide was required for the reaction to proceed. In the next step, hydrolysis of the methyl ester, followed by deprotection of both MOM ethers afforded derivative (27). The low yield was mainly caused by repetitive chromatography which was required to remove all impurities. It seemed that derivative (27), and also the other platencin derivatives synthesized in this project, partially decomposed on silica gel as indicated by the color change of the silica gel after chromatography. The fact that researchers from Merck lost all the isolated platensimycin upon drying the extract with $\mathrm{MgSO}_{4}$ instead of $\mathrm{Na}_{2} \mathrm{SO}_{4}$, further supports the hypothesis that derivative (27) may bind strongly to, or decompose on, polar surfaces [38].

Scheme 8 Synthesis of triazole derivative (27).

Disappointingly, derivative (27) also showed no antibiotic activity towards MRSA and VREF. The lack of activity of derivatives (26) and (27) might be explained by considering the three dimensional structure of platencin (2) in the active site of FabF (Figure 4) in E. coli [39]. From this figure it becomes clear that the linker is twisted $63^{\circ}$ out of the plane of the amide, something which is unfavorable in the case of the carbamate linker due to the hindered rotation around the oxygen-carbon bond. For triazole derivative (78), this twisted conformation is structurally simply impossible. Consequently, the aliphatic and aromatic parts of derivatives (26) and (27) have a completely different orientation and cannot bind in the same way as platencin (2) in the active site of the enzyme. 


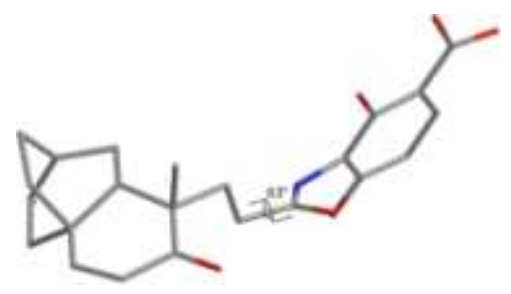

Figure 4 Conformation of platencin (2) in the active site of FabF in E. coli.

\section{Conclusions}

In conclusion, we have developed a short enantiopure synthesis of the platencin derivative dehydrohomoplatencin. The novel ketolide portion of dehydrohomoplatencin was accessed in only two steps with high atom efficiency and includes an unprecedented Prins cyclization reaction. By this exceedingly simple protocol we were able to routinely synthesize the ketolide structure on multigram-scale. The introduction of the aromatic part was performed in moderate overall yield. The completed derivative, dehydrohomoplatencin, proved virtually equipotent to platencin and only lacked activity against $S$. pneumoniae. Substitution of the amide functionality in the linker of dehydrohomoplatencin by a carbamate or triazole group resulted in a complete loss of activity. These findings can be rationalized by inherent conformational restrictions for the new linkers as compared to the amide linker in platencin.

\section{Acknowledgements}

This research has been financially supported (in part) by the Council for Chemical Sciences of The Netherlands Organization for Scientific Research (NWO-CW). We would like to thank J.M.M. Smits (Institute for Molecules and Materials, Radboud University Nijmegen) for the crystallographic analyses.

\section{References}

[1] Lock, R.L. \& Harry, E.J., Cell-Division Inhibitors: New Insights for Future Antibiotics, Nat. Rev. Drug Discov., 7, 324-338, 2008.

[2] Hughes, B., 2009 FDA Drug Approvals, Nat. Rev. Drug Discov., 9, 8992, 2010.

[3] a) Leadbetter, M.R., Adams, S. M., Bazzini, B., Fatheree, P.R., Karr, D.E., Krause, K.M., Lam, B.M.T., Linsell, M.S., Nodwell, M.B., Pace, J.L., Quast, K., Shaw, J.P., Soriano, E., Trapp, S.G., Villena, J.D., Wu, T.X., Christensen, B.G. \& Judice, J.K., Hydrophobic Vancomycin 
Derivatives with Improved ADME Properties: Discovery of Telavancin (TD-6424), J. Antibiot., 57, 326-336, 2004.

b) Corey, G.R., Stryjewski, M.E., Weyenberg, W., Yasothan, U. \& Kirkpatrick, P., Phase 2, Randomized, Double-Blind, Dose-Ranging Study Evaluating The Safety, Tolerability, Population Pharmacokinetics, and Efficacy of Oral Torezolid Phosphate in Patients with Complicated Skin and Skin Structure Infections, Nat. Rev. Drug Discov., 8, 929-930, 2009.

[4] Spellberg, B., Powers, J.H., Brass, E.P., Miller, L.G. \& Edwards, J.E., Trends in Antimicrobial Drug Developments: Implications for The Future, Clin. Infect. Dis., 38, 1279-1286, 2004.

[5] DiMasi, J.A., Hansen, R.W. \& Grabowski, H.G., The Price of Innovation: New Estimates of Drug Development Costs, J. Health Econ., 22, 151-185, 2003.

[6] Hughes, B., 2008 FDA Drug Approvals, Nat. Rev. Drug Discov., 8, 10$11,2009$.

[7] Wang, J., Soisson, S.M., Young, K., Shoop, W., Kodali, S., Galgoci, A., Painter, R., Parthasarathy, G., Tang, Y.S., Cummings, R., Ha, S., Dorso, K., Motyl, M., Jayasuriya, H., Ondeyka, J., Herath, K., Zhang, C., Hernandez, L., Allocco, J., Basilio, Á., Tormo, J.R., Genilloud, O., Vicente, F., Pelaez, F., Colwell, L., Lee, S.H., Michael, B., Felcetto, T., Gill, C., Silver, L.L., Hermes, J.D., Bartizal, K., Barrett, J., Schmatz, D., Becker, J.W., Cully,D. \& Singh, S.B., Platensimycin is a Selective FabF Inhibitor with Potent Antibiotic Properties, Nature, 441, 358-361, 2006.

[8] a) Jayasuriya, H., Herath, K.B., Zhang, C., Zink, D.L., Basilio, A., Genilloud, O., Diez, M.T., Vicente, F., Gonzalez, I., Salazar, O., Pelaez, F., Cummings, R., Ha, S., Wang, J. \& Singh, S.B., Isolation and Structure of Platencin: a FabH and FabF Dual Inhibitor with Potent Broad-Spectrum Antibiotic Activity, Angew. Chem. Int. Ed., 46, 46844688, 2007.

b) Wang, J., Kodali, S., Lee,S.H., Galgoci, A., Painter, R., Dorso, K., Racine, F., Motyl, M., Hernandez, L., Tinney, E., Colletti, S.L., Herath, K., Cummings,R., Salazar, O., González, I., Basilio, A., Vicente, F., Genilloud, O., Pelaez, F., Jayasuriya, H., Young, K., Cully, D.F. \& Singh, S.B., Discovery of Platencin, a dual FabF and FabH Inhibitor with In Vivo Antibiotic Properties, Proc. Natl. Acad. Sci. USA, 104, 7612-7616, 2007.

[9] White, S.W., Zheng, J., Zhang, Y.M. \& Rock, C.O., The Structural Biology of Type II Fatty Acid Biosynthesis, Annu. Rev. Biochem., 74, 791-831, 2005. 
[10] a) Smith, S., Witkowski, A. \& Joshi, A.K., Prog. Lipid Res., 42, 289-317, 2003.

b) Asturias, F.J., Chadick, J.Z., Cheung, I.K., Stark, H., Witkowski, A., Joshi, A.K. \& Smith, S., Structure and molecular organization of mammalian fatty acid synthase, Nat. Struct. Mol. Biol., 12, 225-232, 2005.

[11] a) Campbell, J.W. \& Cronan, J.E., Bacterial fatty acid biosynthesis: targets for antibacterial drug discovery, Annu. Rev. Microbiol., 55, 305332, 2001.

b) Heath, R.J. \& Rock, C.O., Fatty acid biosynthesis as a target for novel antibacterials, Curr. Opin. Investig. Drugs, 5, 146-153, 2004.

c) Zhang, Y.M., White, S.W. \& Rock, C.O., Inhibiting Bacterial Fatty Acid Synthesis, J. Biol. Chem., 281, 17541-17544, 2006.

[12] Cronan, J.E. \& Waldrop, G.L., Multi-subunit acetyl-CoA carboxylases, Prog. Lipid Res., 41, 407-435, 2002.

[13] a) Freiberg, C., Brunner, N.A., Schiffer, G., Lampe, T., Pohlmann, J., Brands, M., Raabe, M., Häbich, D. \& Ziegelbauer, K., Identification and characterization of the first class of potent bacterial acetyl-CoA carboxylase inhibitors with antibacterial activity, J. Biol. Chem., 279, 26066-26073, 2004.

b) Lin, T.W., Melgar, M.M., Kurth, D., Swamidass, S.J., Purdon, J., Tseng, T., Gago, G., Baldi, P., Gramajo, H. \& Tsai, S.C., Structure-based inhibitor design of AccD5, an essential acyl-CoA carboxylase carboxyltransferase domain of Mycobacterium tuberculosis, Proc. Natl. Acad. Sci. USA, 103, 3072-3077, 2006.

[14] De Lay, N.R. \& Cronan, J.E., In vivo functional analyses of the type II acyl carrier proteins of fatty acid biosynthesis, J. Biol. Chem., 282, 20319-20328, 2007.

[15] Gajiwala, K.S., Margosiak, S., Lu, J., Cortez, J., Su, Y., Nie, Z. \& Appelt, K., Crystal structures of bacterial FabH suggest a molecular basis for the substrate specificity of the enzyme, FEBS Lett., 583, 29392946, 2009.

[16] Price, A.C., Zhang, Y.M., Rock, C.O. \& White, S.W., Structure of betaketoacyl-[acyl carrier protein] reductase from Escherichia coli: negative cooperativity and its structural basis, Biochemistry, 40, 12772-12781, 2001.

[17] a) Tasdemir, D., Lack, G., Brun, R., Ruedi, P., Scapozza, L. \& Perozzo, R., Inhibition of Plasmodium falciparum Fatty Acid Biosynthesis: Evaluation of FabG, FabZ, and FabI as Drug Targets for Flavonoids, J. Med. Chem., 49, 3345-3353, 2006. 
b) Kristan, K., Bratkovic, T., Sova, M., Gobec, S., Prezelj, A. \& Urleb, U., Novel inhibitors of beta-ketoacyl-ACP reductase from Escherichia coli, Chem. Biol. Interact., 178, 310-316, 2009.

[18] Marrakchi, H., Choi, K.H. \& Rock, C.O., A new mechanism for anaerobic unsaturated fatty acid formation in Streptococcus pneumoniae, J. Biol. Chem., 277, 44809-44816, 2002.

[19] Wang, H.H. \& Cronan, J.E., Functional replacement of the FabA and FabB proteins of Escherichia coli fatty acid synthesis by Enterococcus faecalis FabZ and FabF homologues, J. Biol. Chem., 279, 34489-34495, 2004.

[20] He, L.Y., Zhang, L., Liu, X.F., Li, X.H., Zheng, M.Y., Li, H.L., Yu, K.Q., Chen, K.X., Shen, X., Jiang, H.L. \& Liu, H., Discovering potent inhibitors against the beta-hydroxyacyl-acyl carrier protein dehydratase (FabZ) of Helicobacter pylori: Structure-based design, synthesis, bioassay, and crystal structure determination, J. Med. Chem., 52, 24652481, 2009.

[21] Lu, H. \& Tonge, P.J., Inhibitors of FabI, an enzyme drug target in the bacterial fatty acid biosynthesis pathway, Acc. Chem. Res., 41, 11-20, 2008.

[22] Heath, R.J. \& Rock, C.O., A triclosan-resistant bacterial enzyme, Nature, 406, 145-146, 2000.

[23] Marrakchi, H., Zhang, Y.M. \& Rock, C.O., Mechanistic diversity and regulation of type II fatty acid synthesis, Biochem. Soc. Trans., 30, 10501055, 2002.

[24] Matsumae, A., Nomura, S. \& Hata, T., Studies on cerulenin. IV. Biological characteristics of cerulenin, J. Antibiot., 17, 1-7, 1964.

[25] Noto, T., Miyakawa, S., Oishi, H., Endo, H. \& Okazaki, H., Thiolactomycin, a new antibiotic. III. In vitro antibacterial activity, J. Antibiot., 35, 401-410, 1982.

[26] For a recent review on the total synthesis of platensimycin, platencin and related analogues see: Palanichamy, K. \& Kaliappan, K.P., Discovery and syntheses of "superbug challengers"-platensimycin and platencin, Chem. Asian J., 5, 668-703, 2010.

[27] a) Nicolaou, K.C., Lister, T., Denton, R.M., Montero, A. \& Edmonds, D.J., Adamantaplatensimycin: a bioactive analogue of platensimycin, Angew. Chem. Int. Ed., 46, 4712-4714, 2007.

b) Nicolaou, K.C., Tang, Y., Wang, J., Stepan, A.F., Li, A. \& Montero, A., Total Synthesis and Antibacterial Properties of Carbaplatensimycin, J. Am. Chem. Soc., 129, 14850-14851, 2007.

c) Nicolaou, K.C., Stepan, A.F., Lister, T., Li, A., Montero, A., Tria, G.S., Turner, C.I., Tang, Y., Wang, J., Denton, R.M. \& Edmonds, D.J., 
Design, synthesis, and biological evaluation of platensimycin analogues with varying degrees of molecular complexity, J. Am. Chem. Soc., 130, 13110-13119, 2008.

d) Yeung, Y.-Y. \& Corey, E.J., A simple, efficient, and enantiocontrolled synthesis of a near-structural mimic of platensimycin, Org. Lett., 10, 3877-3878, 2008.

e) Wang, J., Lee, V. \& Sintim, H.O., Chem. Eur. J., 15, 2747-2750, 2009. f) Shen, H.C., Ding, F.-X., Singh, S.B., Parthasarathy, G., Soisson, S.M., Ha, S.N., Chen, X., Kodali, S., Wang, J., Dorso, K., Tata, J.R., Hammond, M.L., MacCoss, M. \& Colletti, S.L., Synthesis and biological evaluation of platensimycin analogs, Bioorg. Med. Chem. Lett., 19, 1623-1627, 2009.

g) Patra, M., Gasser, G., Pinto, A., Merz, K., Ott, I., Bandow, Julia E. \& Metzler-Nolte, N., Synthesis and Biological Evaluation of Chromium Bioorganometallics Based on the Antibiotic Platensimycin Lead Structure, ChemMedChem., 4, 1930-1938, 2009.

h) Jang, K.P., Kim, C.H., Na, S.W., Kim, H., Kang, H. \& Lee, E., Isoplatensimycin: Synthesis and Biological Evaluation, Bioorg. Med. Chem. Lett., 19, 4601-4602, 2009.

[28] Barykina, O.V., Rossi, K.L., Rybak, M.J. \& Snider, B.B., Synthesis and Antibacterial. Properties of (-)-nor-Platencin, Org. Lett., 11, 5334-5337, 2009.

[29] Tiefenbacher, K., Gollner, A. \& Mulzer, J., Syntheses and Antibacterial Properties of iso-Platencin, Cl-iso-Platencin and Cl-Platencin: Identification of a New Lead Structure, Chem. Eur. J., 16, 9616-9622, 2010.

[30] Waalboer, D.C.J., Schaapman, M.C., van Delft, F.L. \& Rutjes, F.P.J.T., High- pressure entry into platencin, Angew. Chem Int. Ed., 47, 65766578, 2008.

[31] Waalboer, D.C.J., Leenders, S.H.A.M., Schülin-Casonato, T., van Delft, F.L. \& Rutjes, F.P.J.T., Total Synthesis and Antibiotic Activity of Dehydrohomoplatencin, Chem. Eur. J., 16, 11233-11236, 2010.

[32] For a review of the Prins reaction, see:

a) Arundale, E. \& Mikeska, L.A., The olefin-aldehyde condensation. The Prins reaction, Chem. Rev., 51, 505-555, 1952.

b) Adams, D.R. \& Bhatnagar, S.P., The Prins reaction, Synthesis, 661672, 1977.

c) Pastor, I.M. \& Yus, M., The Prins Reaction: Advances and Applications, Curr. Org. Chem., 11, 925-957, 2007.

[33] Nicolaou, K.C., Li, A. \& Edmonds, D.J., Total synthesis of platensimycin, Angew. Chem. Int. Ed., 45, 7086-7090, 2006. 
[34] Nicolaou, K.C., Tria, G.S. \& Edmonds, D.J., Total synthesis of platencin, Angew. Chem. Int. Ed., 47, 1780-1783, 2008.

[35] Heretsch, P. \& Giannis, A., Resorcylic Acid Derivatives for the Synthesis of Platensimycin and Analogues, Synthesis, 2614-2616, 2007.

[36] Wang, J., Soisson, S.M., Young, K., Shoop, W., Kodali, S., Galgoci, A., Painter, R., Parthasarathy, G., Tang, Y.S., Cummings, R., Ha, S., Dorso, K., Motyl, M., Jayasuriya, H., Ondeyka, J., Herath, K., Zhang, C., Hernandez, L., Allocco, J., Basilio, Á., Tormo, J.R., Genilloud, O., Vicente, F., Pelaez, F., Colwell, L., Lee, S.H., Michael, B., Felcetto, T., Gill, C., Silver, L.L., Hermes, J.D., Bartizal, K., Barrett, J., Schmatz, D., Becker, J.W., Cully, D. \& Singh, S.B., Platensimycin is a selective FabF inhibitor with potent antibiotic properties, Nature, 441, 358-361, 2006.

[37] Wang, J., Kodali, S., Lee, S.H., Galgoci, A., Painter, R., Dorso, K., Racine, F., Motyl, M., Hernandez, L., Hinney, E., Colletti, S.L., Herath, K., Cummings, R., Salazar, O., González, I., Basilio, A., Vicente, F., Genilloud, O., Pelaez, F., Jayasuriya, H., Young, K., Cully, D.F. \& Singh, S.B., Discovery of platencin, a dual FabF and FabH inhibitor with in vivo antibiotic properties, Proc. Natl. Acad. Sci. USA, 104, 76127616, 2007.

[38] See supporting information of: Wang, J., Soisson, S.M., Young, K., Shoop, W., Kodali, S., Galgoci, A., Painter, R., Parthasarathy, G., Tang, Y.S., Cummings, R., Ha, S., Dorso, K., Motyl, M., Jayasuriya, H., Ondeyka, J., Herath, K., Zhang, C., Hernandez, L., Allocco, J., Basilio, Á., Tormo, J.R., Genilloud, O., Vicente, F., Pelaez, F., Colwell, L., Lee, S.H., Michael, B., Felcetto, T., Gill, C., Silver, L.L., Hermes, J.D., Bartizal, K., Barrett, J., Schmatz, D., Becker, J.W., Cully, D. \& Singh, S.B., Platensimycin is a selective FabF inhibitor with potent antibiotic properties, Nature, 441, 358-361, 2006.

[39] For the crystal structure of E.coli FabF(C163A) in complex with platencin, see PDB file $3 \mathrm{HO} 2$. 